\title{
Mechanical and microstructural characterization of ST 37 butt joints by friction stir
}

\author{
Kasir $^{1}$ and Sulardjaka ${ }^{1 *}$ \\ ${ }^{1}$ Department of Mechanical Engineering, Diponegoro University. Jl. Prof. Sudharto, SH 50275, \\ Semarang, Indonesia
}

\begin{abstract}
The aim of this research is to investigate mechanical and microstructure characteristic of ST 37 Friction Stir Welded (FSW) butt joints. The rolled plate of ST 37 steel was used as the base material. Tungsten carbide ( $20 \mathrm{~mm}$ on diameter) was used as the tool. The FSW process was conducted on a CNC milling machine. FSW joints were produced at 1500 and $2000 \mathrm{rpm}$ of rotational speeds variation and the transverse speed is constan at $40 \mathrm{~mm} / \mathrm{min}$. Furthermore, the influence of rotational speed on the microstructure and mechanical properties of the joints were investigated based on parameters mentioned above. The tensile test was done based on JISZ 2241 standard. Microhardness was investigated based on ASTM E 384. Joint microstructure was also analyzed by optic microscopy. As a result, FSW joint at $2000 \mathrm{rpm}$ tool rotation shows higher tensile strength, yield strength and percentage of elongation in compare to $1500 \mathrm{rpm}$ rotaton speed. In addition, its tensile strength is about $5 \%$ lower than Base Material (BM) which its ductility decreases up to $30 \%$.
\end{abstract}

\section{Introduction}

Friction Stir Welding (FSW), one of newly welding processes is unveiled by The Welding Institute (TWI), England at 1991 [1]. It utilizes friction produced by contact between tool and specimens in solid-state. It is might be promising welding process which helds precision joints better than the one encountered in fusion welding [2]. In its development, researchers tend to conduct research in stainless steel [3-5], aluminium [6-7], and steel [8-14]. Its principle is joining two plates which is similar or dissimilar in shape using tool that rotates and passes through along the plate. It performs under conditions which are shoulder is fully contacted and the pin is completely inserted and moves in transverse direction towards the weld. Consequently, the transverse and rotated effects of the pin and shoulder breed heat which softens the specimen in solid-state and welds the plates [15]. Some findings explore microstructure and mechanical properties of dissimilar materials such as joining ST 37 and stainless steel 304 [16]. Due to this, we have intention on delving into further information of mechanical properties and microstructure study of weldments performed in high rotational speed on carbon steel ST 37. The reason why we chose ST 37 because of some considerable advantages such as light in weight and good in formability.

\footnotetext{
*Corresponding author: sulardjaka@undip.ac.id
} 


\section{Experimental procedure}

The material used in the research was rolled plate of ST $37(100 \times 70 \times 30 \mathrm{~mm})$. The shouldered pin tool is cone-pin shaped tool made form Tungsten Carbide as shown in Fig.1. FSW processes were done by contacted the rotating tool into the material surfaces with feeding depth $0,02 \mathrm{~mm}$. Then, the rotating tool was moved in transverse direction with velocity 40 $\mathrm{mm} / \mathrm{min}$. The FSW products are shown in Fig.2. Tensile test of FSW joint was conducted on Shimadzu UH1000 kNI tensile machine based on JIZ 2241 standard test. Microhardness of FSW joining was tested based on ASTM E 384 by Mitutoyo Micro Vickers Hardness Testing Machines HM-210. The microstructure was analyzed by optic microscopy on $\mathrm{HNO}_{3}$ and $\mathrm{CH}_{3} \mathrm{OH}$ etched specimens.
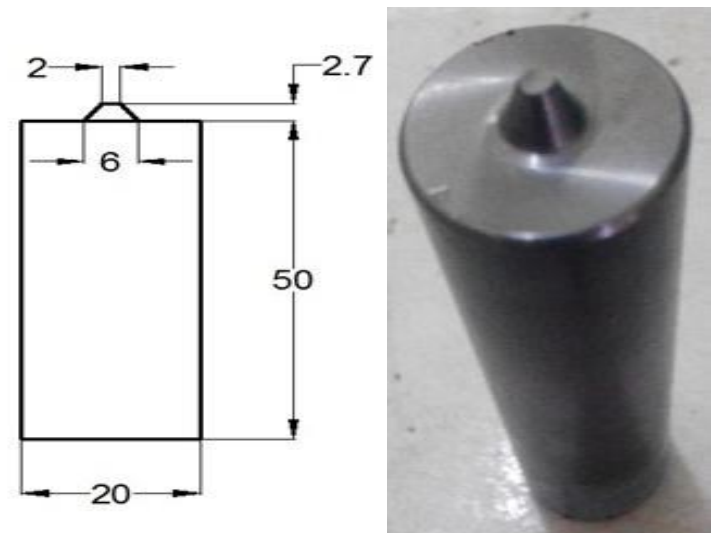

Fig. 1 Dimension of the tool

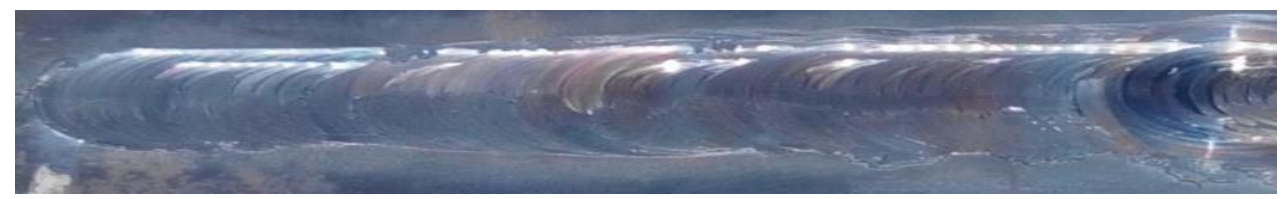

a.

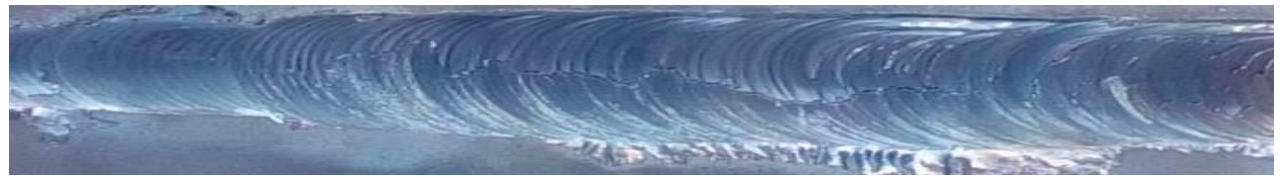

b.

Fig 2. FSW joinning products (a) rotational speed $2000 \mathrm{rpm}$ (b) rotational speed $1500 \mathrm{rpm}$

\section{Result and discussion}

\subsection{Tensile test}

St 37 with a $30 \mathrm{~mm}$ thickness were successfully welded at all given welding conditions. The tensile strentgh of raw material, FSW joinning at $2000 \mathrm{rpm}$ and $1500 \mathrm{rpm}$ rotational speed is shown in Table 1. Yield strength (YS) and ultimate tensile strength (UTS) of the stirred zone tend to increase with an increasing tool rotating speed. The yield strength of specimens carried out under $2000 \mathrm{rpm}$ reached a peak at $329 \mathrm{MPa}$ which was higher than other specimens were about $315 \mathrm{MPa}$ and $280 \mathrm{MPa}$ respectively. On the other hand, the Ultimate Tensile Strength (UTS) of raw material peaked up at $372 \mathrm{MPa}$ which higher than other performed specimens of different rotational speed which are $350 \mathrm{MPa}$ for $2000 \mathrm{rpm}$ and 331 
MPa for $1500 \mathrm{rpm}$. To sum up, specimen which welded by $2000 \mathrm{rpm}$ has better elongation at value $25 \%$ which compares to $1500 \mathrm{rpm}$ at value $10 \%$.

Table 1. Tensile properties of raw material, FSW $1500 \mathrm{rpm}$ and FSW $2000 \mathrm{rpm}$

\begin{tabular}{|l|l|l|l|}
\hline \multicolumn{1}{|c|}{ Specimen } & YS (MPa) & UTS (MPa) & Elongation (\%) \\
\hline Raw material ST 37 & 315 & 372 & 36 \\
\hline FSW 2000 rpm & 329 & 350 & 25 \\
\hline FSW 1500 rpm & 280 & 331 & 10 \\
\hline
\end{tabular}

\subsection{Hardness test}

Microhardness result was processed in 15 points which were started at a point in the middle of Stir Zone (SZ) and 7 points every $1 \mathrm{~mm}$ in range on each side where it was located on Thermo-Mechanical Affected Zone (TMAZ), Heat Affected Zone (HAZ) and Base Metal (BM). It was illustrated in graph that was shown in Fig. 3. A SZ with a tool rotating speed of 1500 - $2000 \mathrm{rpm}$ showed a high hardness are around $250 \mathrm{Hv}$, while the hardness of the $\mathrm{BM}$ is around $150 \mathrm{Hv}$. However, it is found that $\mathrm{SZ}$ of $1500 \mathrm{rpm}$ was higher than that $2000 \mathrm{rpm}$ speeds. The SZ points of specimens in variance of rotational speed had highest hardness, they reached peaks at $240.7 \mathrm{HV}$ and $239.0 \mathrm{HV}$ for $1500 \mathrm{rpm}$ and $2000 \mathrm{rpm}$ respectively. Otherwise, the lowest hardness was found in BM.

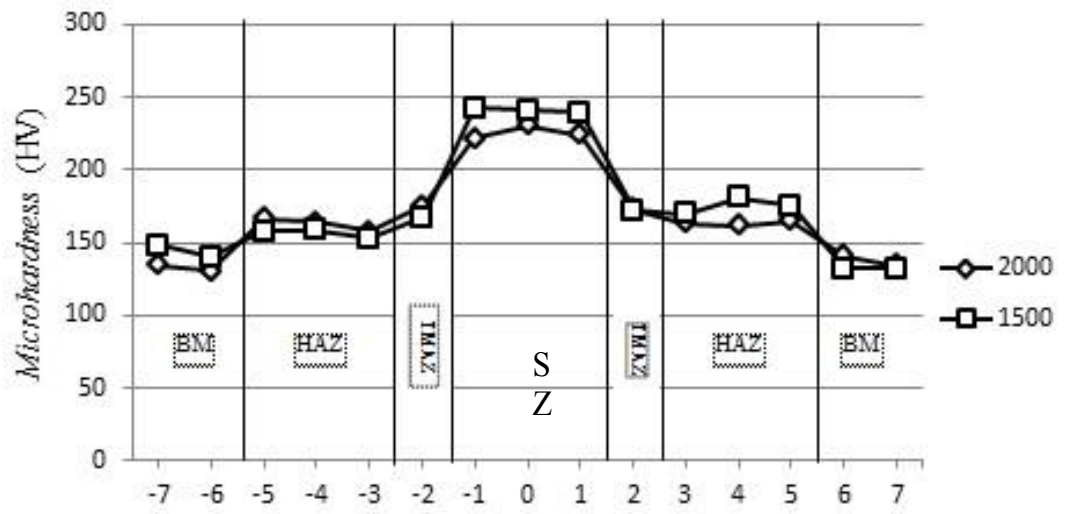

Fig. 3. Hardness distributions of friction stir welded St 37 steel at various tool rotating speeds

\subsection{Microstructure study}

Optical micrographs of friction stir welded St 37 steels in the transverse cross section are shown in Fig. 4. and Fig. 5. The microstructure of SZ and WZ defines a change in the shape of ferrite and pearlite grains where the ferrite and pearlite grains are getting smaller than BM. 


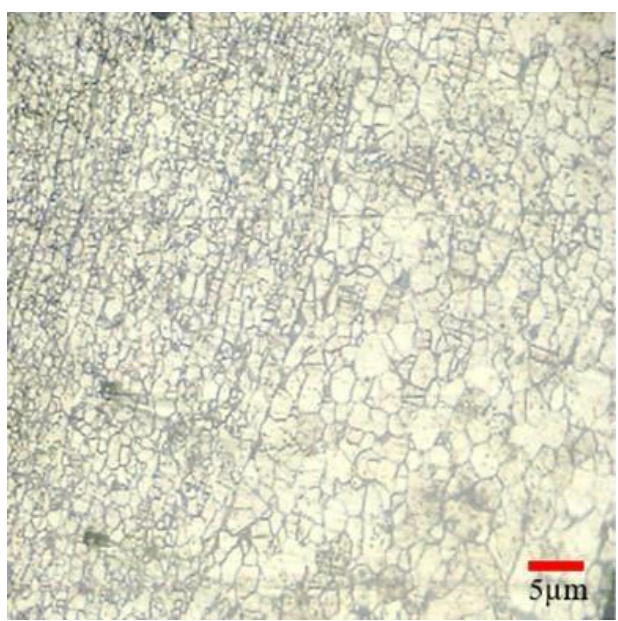

a.

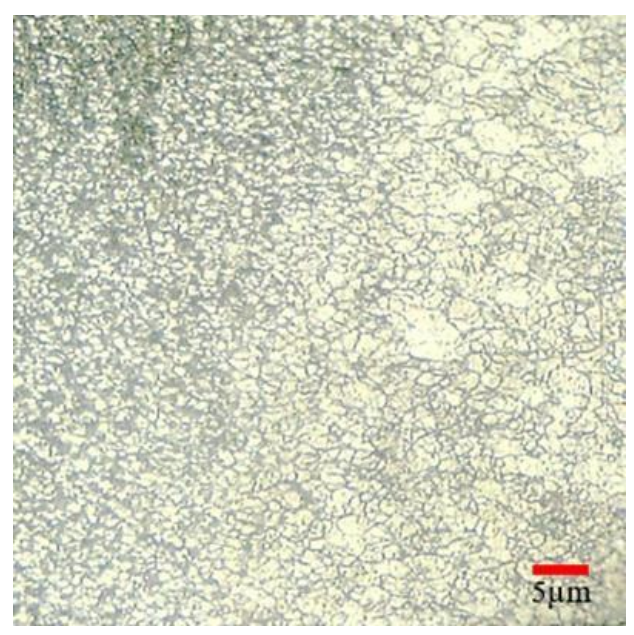

b.

Fig. 4. Microstructure images of SZ and HAZ (a) $1500 \mathrm{rpm}$ (b) $2000 \mathrm{rpm}$

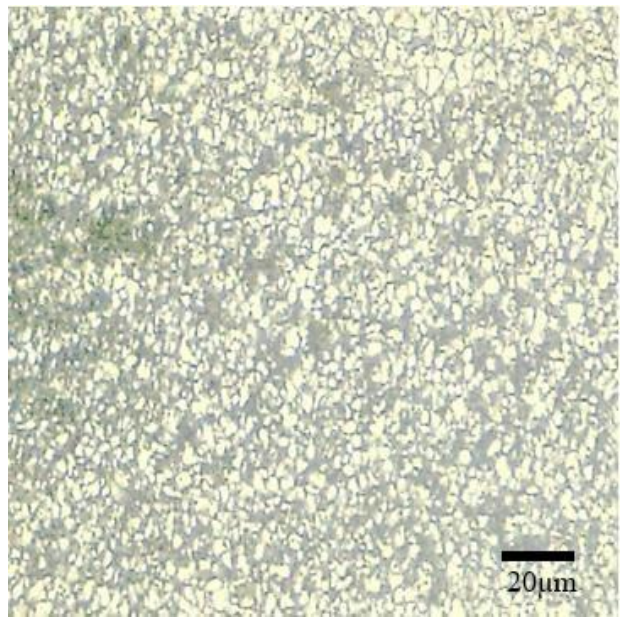

a.

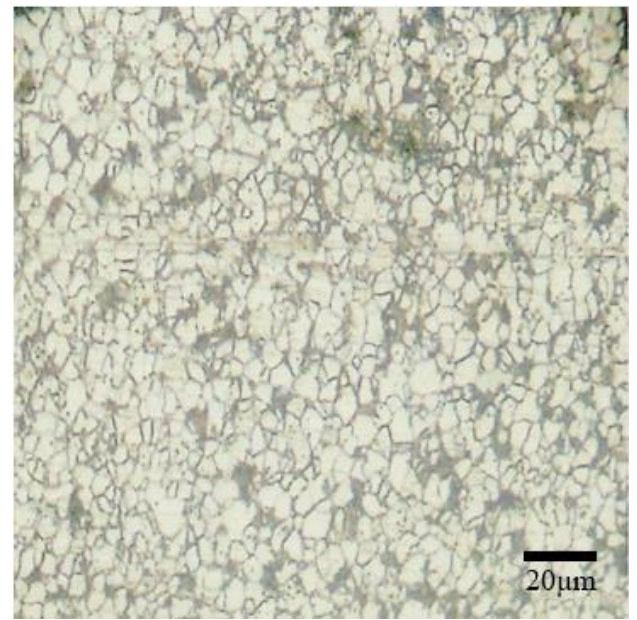

b.

Fig. 5. Microstructure images of Weld Zone (a) $1500 \mathrm{rpm}$ (b) $2000 \mathrm{rpm}$

\section{Conclusion}

It can be proven that Friction Stir Welding can be performed in Carbon Steel St 37 under parameters: tranverse speed at $40 \mathrm{~mm} / \mathrm{min}$ and variances of high rotational speed at $2000 \mathrm{rpm}$ and $1500 \mathrm{rpm}$. FSW with $2000 \mathrm{rpm}$ tool rotation give higher tensile strength than FSW at $1500 \mathrm{rpm}$ rotation. Stir Zones of FSW products have greater value of hardness than base metal.

\section{References}

1. T. M. Wayne \& Nicholas, E. D., Friction stir welding for the transportation industries, 18, 269-273 (1997)

2. R. Seerangan, V. Balasubramanian, S. Malarvizhi, A.G. Rao, Def.. Tech., 11, 308-317 (2015)

3. A.P. Reynolds, W. Tang, T.G. Herold, H. Prask, Scripta Mater, 48, 1289-1294 (2003) 
4. J.C. Lippold, D.J. Kotecki, Welding metallurgy and weldability of stainless steels, (2005)

5. S.H.C. Park, Y.S. Sato, H. Kokawa, K. Okamoto, S. Hirano, M. Inagaki, Sci Tech. Weld. Joint., 10 (2005)

6. S.Y. Tarasov, V.E. Rubtsov, E.A. Kolubaev, Wear, 318, 130-134 (2014)

7. N. Z. Khan, Z. A. Khan, A. N. Siddiquee, Mater. To. Proceedings 2, 1450-1457 (2015)

8. V. L. Manugula, K. V. Rajulapati, G. Madhusudhan Reddy, R. Mythili, K. Bhanu Sankara Rao, Met. \& Mater. Transc. A., 48, 3702-3720 (2017)

9. R. Ramesh, I. Dinaharan, Ravi Kumar, E.T. Akinlabi, Mater. Sci. \& Eng, A687, (2017)

10. A.Pradeep, S. Muthukumaran, Mater \& Des., 5, 25-35 (2013)

11. Y. Liu, D. Dong, L. Wang, X. Chu, P. Wang, M. Jin, Mater \& Des., A627, 296-305 (2015)

12. L.N. Brewer, M.S. Bennett, B.W. Baker, E.A. Payzant, L.M. Sochalski-Kolbus. Mater. Sci. \& Eng., A647, 313-321 (2015)

13. A. M. El-Batahgy, T. Miura, R. Ueji, H. Fujii, Mater. Sci. \& Eng.,A651, 904-913 (2016)

14. J. Rodriguez, A.J. Ramirez, Mater Character, 110, 126-135 (2015)

15. B. R. Singh, A Hand Book on Friction Stir Welding, (2012)

16. M. Jafarzadegan, A.H. Feng, A. Abdollah-zadeh, T. Saeid, J. Shen, H. Assadi, Mater. Charact., 74, 23-41 (2012) 